\title{
Pedagogical Approaches to Aviation Phraseology and Communication Training in Collegiate Flight Programs
}

\author{
Kitty Campbell-Laird \\ Purdue University
}

\begin{abstract}
The purpose of this study was to determine how collegiate aviation programs in the United States provide aviation phraseology and communication training. Possible differences in pedagogical approaches when teaching aviation phraseology to native vs. non-native speakers of English were also explored. This work builds on literature (Day, 2004; Mathews, 2004; Philips, 1991; Prinzo \& Britton, 1993; Ragan, 2002; Verhaegen, 2001) which suggests that failure to use standardized aviation phraseology, improper pilot/air traffic controller communications procedures, and lack of English language proficiency threaten flight safety. This study explored aviation phraseology and communication instruction curriculum in use at accredited university aviation flight programs. The study was conducted in two phases. In the first phase, administrative faculty from each of the sixteen Council on Aviation Accreditation (CAA) accredited flight programs completed an online survey. Faculty administrators from seventy-five percent of the accredited flight programs participated in a follow-up phase including two focus groups and one interview. While not generalizable to all flight training institutions, recommendations are discussed in terms of potential research applications for collegiate aviation programs.

\section{INTRODUCTION}

English has been chosen as the official language of flight in the United States and continues to be the recommended lingua franca for international use (Crystal, 1997). In some cases, a lack of English proficiency of pilots or controllers has led to disastrous and even fatal catastrophes. While miscommunications between flight crews and air traffic control (ATC) personnel may have been only one aspect of these incidents and accidents, the lack of ability for all parties involved to understand crucial directions via a common English may have been the most important contributing factor leading to these tragedies. Without agreed upon standards for English proficiency and common phraseology, the aviation industry continues to be at risk for future language related accidents (Day, 2004; Mathews, 2004; Philips, 1991; Prinzo \& Britton, 1993; Ragan, 2002; Verhaegen, 2001).

Literature suggests that air traffic communications often deviate from standard phraseology in emergency situations towards a more conversational style. Since this phenomenon commonly occurs, an English proficiency beyond the basic understanding of aviation phraseology may be necessary

(Mathews, 2004). In addition, a cultural awareness of the variety of English spoken in the country or countries encountered during flight may help avoid misunderstandings and miscommunications (Dyck, A., personal communication, December 8, 2001).

\section{Statement of the Problem}

Federal Aviation Administration (FAA) written examinations address some phraseology and communication procedures in a textual format, but do not provide an assessment of oral aviation English proficiency or actual communication performance. The only subjective measures of pilot communication performance are assessed by flight examiners during practical flight examinations (Nordwall, 1997).

Training in aviation phraseology and communication primarily occurs in initial ground and flight instruction. Actual aviation communication in the United States often deviates from prescribed phraseology. Even when strictly adhered to, FAA phraseology can differ from International Civil Aviation Organization (ICAO) recommended phraseology. Regional variations in usage may also occur and further complicate negotiation of meaning (Ragan, 2002).
\end{abstract}


At the time of this writing, new ICAO language policies which promote globalized standards of aviation phraseology had been adopted in 2004 and were slated for implementation in 2008 (ICAO, 2004).

\section{Purpose of Study}

The purpose of this investigation was to determine how collegiate aviation programs in the United States provide phraseology and communication training. Possible differences in pedagogical approaches when teaching aviation phraseology to native vs. non-native speakers of English were also explored.

\section{METHODOLOGY}

The study focused on the discovery of descriptive information regarding curriculum in collegiate aviation phraseology and communication flight training. An initial survey was followed up by focus groups and one interview. While not anticipated, the interview was conducted at the request of a subject who was unable to attend one of the focus groups, but still wished to participate in the study while on site at the UAA fall education conference.

\section{Participants}

University aviation flight programs which exemplify academic excellence in ab initio training were examined. The entire population of CAA member schools with accredited flight programs was selected. (A full listing of the specific institutions is in Table A-1, located in the appendix.) These programs were chosen because the schools have already passed rigorous accreditation protocols, have demonstrated excellence, and have met high standards criteria.*Methodology for obtaining accreditation is detailed on the CAA website (Council on Aviation Accreditation, 2005).

\section{Instrumentation}

A survey instrument was created by the author to assess the curriculum of CAA member schools with accredited flight programs. This instrument attempted to determine the emphasis of phraseology and communication training in the university aviation environment.

Prior to the design of the survey, an Internet search was conducted along with content analysis of the websites to learn about general public information regarding the scope and general policies of the institutions to be surveyed. (URLs for the program websites are listed in the references.) The instrument was pilot tested with Purdue University flight faculty to insure the validity of the survey. The survey was also tested for technical stability with Purdue University IT staff before administering to the survey participants.

The online survey was estimated to take 1015 minutes to complete and consisted of 22 demographic and curriculum based questions and 6 perception questions. Since the survey was administered via the Internet, authentication and security were provided by the assignment of a randomly generated five-digit unique ID for each institution. The survey site was only accessible with authentication via this ID.

\section{Focus Groups}

Two focus groups were conducted onsite at the 2005 University Aviation Association (UAA) fall education conference and an interview guide was developed to ensure standardization between groups. The two groups consisted of flight faculty and administrators from eleven of the sixteen CAA accredited flight programs. Some, but not all of the focus group subjects had also participated in the survey phase of the study.

\section{Interview}

Although not anticipated in the follow-up design, an interview was conducted in order to allow a subject who was in attendance at the UAA fall education conference but unable to participate in the scheduled focus groups to contribute to the study. Comments from the interview were aggregated with those of the focus groups to protect the anonymity of the participant.

\section{RESULTS}

\section{Survey}

Descriptive information about each program, such as student population demographics, admission requirements, etc., was collected from survey respondents and related to curriculum content and perception responses. Frequency and variety of curriculum content responses were categorized. Respondents were asked to answer all questions for the 2005-6 
academic year unless otherwise specified. This time frame was selected to obtain a snapshot of current data which could be evaluated within and among programs.

Program Demographics Enrollment ranged from 150 to 1400 students with $75 \%$ of the programs reporting an enrollment of less than 350 students. Figure A-1, located in the Appendix, provides a graphical illustration of enrollment by program. Only 25\% were larger programs with enrollments of more than 350 students. International student enrollment was low in all programs, ranging from one to fortyfive students with $75 \%$ of the programs reporting fifteen or fewer international students. Figures A-2, A-3, \& A-4, located in the Appendix, provide graphical illustrations of the international student population by program.

The survey provided 82 of the most frequently mentioned countries of origin for international students attending North American Colleges and Universities from which to choose and also provided an opportunity to add countries not listed (Purdue University International Students and Scholars, 2004, p. 6). Refer to Table A-2, located in the the appendix, for a full listing of countries. Notably, Japan had the highest frequency by far with twelve programs reporting international students from that nation. Significantly lower, but next in frequency were Brazil, Canada, France, and Germany, each with six programs reporting to have had students from these countries, and India, Jamaica, Saudi Arabia, and the United Kingdom, each with five programs reporting to have had students from these countries.

Participants were asked to specify the TOEFL (Test of English as a Foreign Language) score requirements for admission of international students and had options to answer for either or both the paper based test (PBT) or the computer based test (CBT) in the event that faculty administrators were familiar with only one scoring system and not the equivalent in the other format. Results are detailed in Table 1 below.

Table 1. Program Minimum Acceptable TOEFL Score

TOEFL PBT

Score

400

450

500

550

600

650 Equivalent CBT Score
Number of Programs

\begin{tabular}{cccc}
\hline 400 & 97 & 0 & $0.00 \%$ \\
450 & 133 & 2 & $12.5 \%$ \\
500 & 173 & 7 & $43.75 \%$ \\
550 & 213 & 5 & $31.25 \%$ \\
600 & 250 & 1 & $6.25 \%$ \\
650 & 280 & 1 & $6.25 \%$ \\
\hline
\end{tabular}

Thirteen flight programs indicated the same TOEFL requirement as their institution. No flight programs made accommodations for lower TOEFL scores, but three programs indicated higher admissions requirements than their institution.

Program Curriculum To determine all possible courses within the curriculum that might impact aviation phraseology and communication training, the survey listed nine options and gave an opportunity to provide other courses not included in the list. Participants were instructed to choose all courses within the curriculum that they felt emphasized aviation phraseology and communication training. Multiple course responses were chosen by each program. Results are detailed in Table 2 below. 
Table 2. Aviation Phraseology and Communication Training Emphasis

\begin{tabular}{lcc}
\hline Courses & Number of Programs & Response Rate \\
\hline Private ground & 14 & $87.5 \%$ \\
Private flight & 13 & $81.25 \%$ \\
Instrument ground & 15 & $93.75 \%$ \\
Instrument flight & 14 & $87.5 \%$ \\
Commercial ground & 12 & $75.0 \%$ \\
Commercial flight & 13 & $81.25 \%$ \\
Flight simulator & 11 & $68.75 \%$ \\
Crew resource mgmt. (CRM) & 12 & $75.0 \%$ \\
Air traffic control (ATC) & 10 & $62.5 \%$ \\
$*$ Other & 1 & $6.25 \%$ \\
\hline
\end{tabular}

*Other: special aviation communication course

Respondents were instructed to choose all aviation phraseology and communication standards currently taught in the program

curriculum. Results are detailed in Table 3 below.

Table 3. Communication Standards Emphasized

\begin{tabular}{lcc}
\hline Communication Standard & Number of Programs & Response Rate \\
\hline FAA & 16 & $100.0 \%$ \\
ICAO & 8 & $50.0 \%$ \\
Airline industry & 10 & $62.5 \%$ \\
Local and regional norms & 1 & $6.25 \%$ \\
Other & 0 & $0.0 \%$ \\
\hline
\end{tabular}

Programs were provided four options and given an opportunity to name specific textbooks utilized and specify resources not previously listed. Respondents were instructed to select all resources in use with multiple combinations of resources possible. Results are detailed in Table 4 below.

Table 4. Aviation Phraseology and Communication Skills Instructional Resources

\begin{tabular}{lcc}
\hline Resource & Number of Programs & Response Rate \\
\hline FAR/AIM & 15 & $93.75 \%$ \\
ICAO manual of RTF & 5 & $31.25 \%$ \\
ATC manual & 8 & $50.0 \%$ \\
$*$ Text book & 3 & $18.75 \%$ \\
$* *$ Other & 2 & $12.5 \%$ \\
\hline
\end{tabular}

*Text specified: Jeppessen **Other resources: Comm 1 software and instructor experience

The survey provided three options for aviation phraseology and communication skills practice and gave an option to provide specific opportunities not previously listed. Participants could provide multiple responses and were instructed to select all categories that applied to their program. Results are detailed in Table 5 below.

Table 5. Aviation Phraseology and Communication Skills Practice Opportunities

\begin{tabular}{lcc}
\hline Skills Practice Opportunity & Number of Programs & Response Rate \\
\hline ATC/pilot computer simulation & 13 & $81.25 \%$ \\
NIFA team participation & 9 & $56.25 \%$ \\
CFI tutoring & 10 & $62.5 \%$ \\
$*$ Other & 2 & $12.5 \%$ \\
\hline
\end{tabular}

*Other: language tutoring, internships and senior projects 
Twelve programs reported offering English language remediation. All of the potential respondents reported that the institution provided such instruction rather than the flight program. Respondents were provided five options of typical ESL instruction choices. Results are detailed in Table 6 below.

Table 6. Type of English Language Instruction

\begin{tabular}{lcc}
\hline Instruction Offered & Number of Programs & $*$ Response Rate \\
\hline Aviation specific English & 3 & $25.0 \%$ \\
General English & 11 & $91.6 \%$ \\
Computer assisted (CAI) & 4 & $33.3 \%$ \\
One-on-one tutoring & 6 & $50.0 \%$ \\
Small group communication & 3 & $25.0 \%$ \\
Other & 0 & $0.0 \%$ \\
\hline
\end{tabular}

*Response Rate: percentage of 12 programs with ESL instruction

Participant Perceptions The survey concluded with six perception questions with responses on a traditional five point Likert scale. Possible responses included: strongly agree, agree, undecided/neutral, disagree, and strongly disagree. For each question, respondents were asked to give their perception of the flight program.

Ground school instructors were perceived to most effectively promote the usage of standardized aviation phraseology, closely followed by flight training instructors and simulator instructors. All instructor categories had a median response of strongly agree. Experience of instructors was seen as a positive factor, but not strongly perceived to influence quality of aviation phraseology and communication training with a median response between undecided/neutral and agree.

In regards to how the flight program curriculum addressed aviation phraseology and communication instruction, respondents felt that the curriculum addressed industry jargon with a median response of agree; however, most participants were either ambivalent or did not feel the program had an adequate global perspective towards aviation communication with a median response of undecided/neutral.

Data Correlations In addition to analyzing the individual survey questions, responses which were anticipated to have a possible relationship in the design phase of the survey were correlated. Statisticians cautioned although the entire population was surveyed, such a small total population $(\mathrm{N}=16)$ may not yield statistically significant findings and all calculations should be viewed in context, since outliers could drastically alter outcomes. The statistical packages Systat and R were used to calculate correlations. The following correlations were done using Kendall's tau coefficient, a correlational method for ordinal variables. Spearman's rank correlation could have obtained qualitatively similar results; however, the coefficient was intended for use with continuous data that does not meet the assumptions of the parametric Pearson's correlation. Kendall's tau also accounts for ties in rank in the ordinal responses. Thus, if multiple participants selected the same response, the results of the analysis would not be biased. Spearman's correlation coefficient uses the average of the tied scores to account for this, but because such averages are meaningless for ordinal variables, it was a less preferable means of analysis (Conover, 1980).

The first correlation explored whether programs with a higher TOEFL score for admission tended to omit offering English language instruction. The assumption was that a higher TOEFL score might be seen as an adequate means for screening potential international students and those students with demonstrated English language proficiency may not need ESL remediation. The anticipated outcome that schools with higher TOEFL scores tended to not offer English language instruction proved to be significant as shown in Table 7 below. 
Table 7. TOEFL Score and English Language Instruction

$\begin{array}{lcc}\text { Kendall's tau } & \text { p-value } & \text { z-test } \\ -0.5539117 & 0.02045 & -2.318\end{array}$

$p<.05$ range of TOEFL score is significantly correlated to offering ESL instruction

Curriculum emphasis of ground school instruction was correlated with the perceived promotion of standardized aviation phraseology by the respective instructors. Although private and instrument emphasis/instruction did not demonstrate a relationship, commercial emphasis/instruction had a significant relationship as shown in Table 8 below.

Table 8. Ground School Emphasis and Perceived Ground Instruction

\begin{tabular}{lccc}
\hline Ground School & Kendall's tau & p-value & z-test \\
\hline Private & 0.1852396 & 0.4631 & 0.7338 \\
Instrument & 0.3977058 & 0.1152 & 1.5755 \\
${ }^{*}$ Commercial & 0.8296298 & 0.001015 & 3.2865 \\
\hline
\end{tabular}

$p<.05 *$ commercial ground school instruction is highly significant

\section{Focus Groups and Interview}

Further discussions with administrative flight faculty from CAA flight programs occurred via two focus groups and one followup interview including $75 \%$ of the total population. In order to ensure standardization between topics discussed, an interview guide was developed. Each question led to group discussion on the topics which provided the following synthesized comments and thematic conclusions.

Curriculum Delivery In regards to standardized curriculum delivery, it was discovered that while many programs delegate English remediation to the larger institution, some programs have aviation specific language courses and even provide individual instruction and seminars for aviation students. The majority of programs charge flight instructors with the primary dissemination of aviation phraseology and communication knowledge. Many programs supplement this knowledge with a specific air traffic control (ATC) course. Simulation is also incorporated with dynamic software, such as Comm 1, which encourages correct pilot and air traffic controller communication and usage of standardized phraseology. In some programs, advanced courses continue emphasizing proper communication procedures by integrating instruction with flight training devices (FTDs) with appropriate usage of pilot/ATC communications. Most programs encourage standardized phraseology and clear communications in Crew Resource Management (CRM) courses. In these advanced pilot training situations, programs reported use of industry standard checklists and responses.

English Language Proficiency When determining English language proficiency for international students, most programs indicated a strong reliance on the Test of English as a Foreign Language (TOEFL) scores as a screening device for candidates admissions to programs. However, even when students had high test scores, some programs noted international students having difficulties with idioms and nuances of conversational English. Some programs reported conducting informal interviews between faculty and prospective international students to further assess English language skills. Once students are admitted to flight programs, language and communication skills are assessed during check rides with examiners and instrument proficiency checks (IPCs) with instructors. Simulation was presented as a helpful option for standardized student self assessment. Some programs reported incorporating ATC software that will not respond properly unless a student uses standardized phraseology. Usage of standardized phraseology is routinely encouraged in many programs by promoting practice with ATC tapes, performing pilot briefings which emphasize standardized phraseology, and using communication card templates for familiarization with standardized phraseology. In some cases, classroom instructors work with students on language proficiency. Other than performance evaluations during check rides, there was little means for assessing aviation 
phraseology and communication proficiency levels of students in a structured standardized method.

International Student Demographics and Cultural Inclusion When discussing philosophies about recruitment of international students and strategies for inclusion of those students once admitted, most programs reported having a small percentage of international students. Cultural differences were noted, such as Asian students' tendency to respond affirmatively even if they do not understand or intend to comply with a directive. Participants also highlighted that when unexpected situations occur, people often revert to conversational language; however, non-native English speakers are primarily taught aviation specific phraseology and many are not able to function at a proficient level in general English outside of standardized communications.

Global Perspective towards Aviation When addressing the philosophies of the CAA flight programs about preparing students for future career paths which may lead to operating in international airspace and on international routes, programs reported that keeping track of alumni was difficult. All programs mentioned alumni association tracking at an institutional level, but individual flight programs did not report a formal standardized mechanism for tracking alumni. Most programs had faculty members who knew about individual graduates' progress. Some programs attempted to track alumni progress and kept current biographies of graduates, but participants noted the difficulties in keeping such data up to date as the alumni base is very transient. No participants reported keeping current statistical information on all program alumni. Strategies for keeping in contact with alumni included holding student/alumni banquets, doing exit and followup interviews with graduates to assess program needs, and enlisting key faculty and staff to ask for feedback from program alumni.

When asked to share opinions about program attitudes towards a global aviation perspective, some programs reported the advantage of close proximity to international airspace. Participants stated when flight students have the opportunity to fly outside the U.S., most commonly to Canada, Mexico, or the Caribbean, they gain a greater awareness of global differences. Unfortunately, many aviation students do not have the opportunity to fly internationally until after graduation, in many cases years later. One participant stated that the majority of their graduates will experience international flight after graduation in a corporate aviation environment. To try and fill the void in students' collegiate experience, flight faculty at many programs will teach by sharing international flight experiences with students, often highlighting communication concerns. Programs with international students reported that the interaction of U.S. and foreign students was insightful for both parties. Sensitivity to accents and regional differences was noted as a concern, even within the continental U.S. Many participants stated that with so many curricular mandates for flight programs, although important, a global perspective was not a high priority. Some participants felt that since English is the lingua franca of aviation and most flight program students are native speakers of English, there may be little need for emphasis on aviation English.

\section{DISCUSSION}

In regards to specific survey content, the author was surprised that so many international student countries of origin had at one time had representation at a CAA accredited flight program. With only sixteen programs, it was anticipated that many of the eighty-two countries listed would not be selected; however, only four of the eighty-two listed countries were not selected by at least one program. While this response is not representative of current student demographics, it does highlight the challenges that a varied international student base presents. Unlike contract programs where a large group of homogeneous students with similar first language backgrounds may come from a specific country to train in the U.S., the academic flight programs may find it hard to address concerns from the international students' first language perspective making curriculum design more difficult. When adding in native speakers of English, the curriculum design is even more complex. 
In follow-up focus groups it was determined that most programs left tracking of alumni to institution based organizations such as a university alumni association or development office. This leads to a bigger issue of a reported overall lack of resources at the program level. Budgets dictate that faculty and staff duties must be prioritized and many things are delegated to larger institution infrastructure. This may serve short term financial concerns, but it may not address the best interests of the program in the long run. Strategic planning for future vision of flight programs can benefit greatly from program alumni input. While keeping addresses current, alumni association and development organizations may not be addressing program concerns.

\section{CONCLUSIONS}

The strategy for programs to use higher TOEFL admission scores as a means to avoid providing English language instruction had a high correlation. This option for screening is not necessarily valid as the PBT and CBT TOEFL do not currently have a means for assessing oral performance through spoken English. The new Ibt (Internet based test) will incorporate a test of spoken English and attempts to address oral proficiency better than currents tests which rely on reading and listening comprehension. The Ibt may cause another concern in that it may not be available in poorer countries without technological infrastructure.

The researcher posited anecdotal evidence that much flight training is conducted by student CFIs. While this view could not be substantiated in survey responses due to the aggregation of ground and flight instructor personnel types, the theory was supported in focus group discussions. This raises concerns for the lack of formal structure in curriculum for aviation phraseology and communication training. Newly trained student CFIs need a standardized method for conveying aviation phraseology and communication skills to students. This is especially important since new CFIs have just crossed over into the role of instructor and may be overwhelmed by the many flight training procedures which need to be taught to their flight students. Designing a standardized curriculum for the dissemination of this information will take pedagogical research. Again the author is confronted with concerns about program resources and priorities.

Program resources and priorities are an additional concern when it comes to outsourcing English language instruction and tracking of alumni. While larger institution organizations may have infrastructure in place to address major concerns such as general English proficiency and basic graduate demographic information, these organizations may not address specific program concerns. There may be opportunities to collaborate with university organizations to optimize resources. In the case of English language instruction, ESL specialists may have more experience working with a range of first language learning concerns. Perhaps flight program personnel could offer to provide an aviation context for ESL instruction. Likewise, many university alumni and development organizations may be able to work with programs to create tools to track alumni and gather better information for all parties involved. It may just take a commitment of time to explore possibilities for collaborative ventures. Most universities prefer to have a coordinated approach for communicating with alumni. There may be ways to utilize databases and other institution infrastructure and avoid duplicating efforts, thereby gaining resources.

From a philosophical perspective, the author is concerned about the lack of attention to native speakers of English in regards to aviation phraseology and communication curriculum. One should not assume that native speakers of English will encounter little difficulty with aviation phraseology and communication protocols just because these registers (a sociolinguistic term which according to Mesthrie, Swann, Deumert, \& Leap, “...denotes variation in language according to the context in which it is being used” 2000, p. 72.) are predicated on the English language. The abbreviations, syntax, and lexicon, of radiotelephony is not structured like a natural language. While based on English words, learning aviation phraseology is much like learning a foreign language. Protocols must be learned along with norms for the speech community of the aviation industry. 
ICAO has come furthest in addressing aviation phraseology standards by creating a model for holistic descriptors; however, the Proficiency Requirements in Common English (PRICE) study group did not come away with common assessment tools for oral communication performance in an aviation context or a standardized aviation phraseology and communication training curriculum. ICAO's holistic descriptors are a good first step, but without operationalizing these descriptors into a standardized curriculum they serve only as textual benchmarks. It will take resources and research study by some entity, be it academic, industry, or governmental, to take the next step in assessment and curriculum development for aviation phraseology and communication training.

\section{RECOMMENDATIONS}

Suggestions for future directions in academic curriculum and pedagogy involve a more formally structured approach, including possible incorporation of a standardized aviation specific phraseology and communication course in U.S. flight training programs. This could encompass Aviation English for both native and non-native speakers. Assumptions that native speakers of English do not need specific aviation phraseology and communications instruction may be naive. While ICAO language and communications policies currently slated for implementation in 2008 are primarily focused on general English language proficiency, competency in standardized aviation phraseology is also paramount for flight safety. Native speakers of English will have an advantage when encountering emergency situations in the event that communications revert to conversational English in lieu of standardized phraseology; however, failing to use proper phraseology and protocol, such as neglecting to declare a fuel emergency, may have disastrous outcomes such as those in the Avianca crash of 1991.

For non-native speakers of English, courses could ideally be tailored to address concerns from the perspective of the students' first language. This could be difficult, since the survey found that international students in the CAA accredited flight programs typically came from many different countries; therefore making this suggestion hard to structure into a standardized aviation curriculum. However, in cases where large groups of students come from the same country, as is the case in most contract programs, first language issues could be more easily addressed. Also in cases when ESL specialists are employed, these professionals should be more equipped to understand the learners' first language pedagogical issues. Strategies to address specific cultural issues could be implemented to enhance learning and address communication with the students' first language perspective in mind.

A structured approach to implementing aviation phraseology and communication training initiatives is crucial for successful assimilation into the professional pilot's skill set. To that end, emphasizing usage of standardized phraseology and communications protocol throughout the flight program curriculum is highly recommended. Perceptions of the participants surveyed reflected a need for higher quality of phraseology and communication instruction in early flight training with an emphasis on promoting usage of standardized phraseology in ab initio training efforts such as ground school and flight training instruction. Again, it is important to note that much of early flight training may be conducted by newly trained student CFIs with limited teaching experience. Without a structured and standardized aviation phraseology and communication protocol curriculum, student CFIs may become overwhelmed with other, perhaps more crucial, flight responsibilities and pay less attention to enforcing proper communication procedures. Creating strategies and structures which continue to encourage usage of standardized phraseology and communication protocols in advanced flight courses might reinforce proper pilot controller interaction and aid in student retention of aviation language communication policies and procedures.

Based on the results of this study, CAA flight programs do not currently share a global aviation philosophy. Only half of the CAA accredited flight programs surveyed reported teaching ICAO radiotelephony standards while $100 \%$ of the programs indicated teaching FAA 
phraseology and communication standards. While these programs primarily operate in the continental United States, some programs reported participating in international flight activities. In the case of professional flight students, many graduates will operate in international airspace during the course of their careers. Large airports inside the U.S., such as Chicago, LAX, and JFK experience high volumes of international traffic, so professional pilots may encounter international pilots who are more familiar with ICAO phraseology and communication standards without ever leaving domestic airspace. Strategic routine surveys of flight program alumni which track statistics and gather qualitative data might help determine the need for a more global perspective in aviation phraseology and communications training. The structured methods might also assist in prioritizing the most common language and communication issues encountered in commercial flight. These standardized assessment tools could aid in directing future aviation phraseology and communication curriculum.

\section{FURTHER RESEARCH}

Recommended areas for future research include further study of how international academic and commercial flight training institutions address phraseology and communication instruction and curriculum. Studies could also explore if other international and domestic flight training organizations address language issues in their curriculum and if so, how these issues are qualitatively implemented. Are there programs which truly address first language issues for non-native speakers of English? If so, are the first language bias and cultural concerns of the students being targeted? Are we working with subject matter experts in interdisciplinary efforts to address these issues in the most effective manner?

There is much room for further study since this area of inquiry has only recently been broached. Most notably, new ICAO language and communication policies currently slated for implementation in 2008 may drive a need for more research in aviation phraseology and communication assessment, curriculum, and instruction. Philosophically, the aviation flight training industry must first decide that flight safety is dependent on clear communication and that aviation language proficiency is a top priority worthy of the precious and limited resources of time, personnel, and funding. 


\section{REFERENCES}

Arizona State University Aeronautical Management Technology. (2006). website from: http://www.asu.edu/provost/smis/asue/bs/amtpfbs.html

Auburn University College of Business Aviation Management and Logistics. (2006). website from: http://www.business.auburn.edu/departments/aviation

Central Missouri State University Department of Aviation. (2006). website from: http://www.cmsu.edu/x36710.xml

Conover, W. J. (1980). Practical nonparametric statistics (2nd ed.). New York: Wiley.

Council on Aviation Accreditation. (2005). website from: http://www.caaaccreditation.org/methodology.html

Crystal, D. (1997).Why English? The cultural legacy. In English as a global language (pp. 78-112). Cambridge, UK: Cambridge University Press.

Daniel Webster College Aviation. (2006). website from: http://www.dwc.edu/academics/aviation/av_content.shtml

Day, B. (2004). Heightened awareness of communication pitfalls can benefit safety. ICAO Journal, 59(1), 20-22.

Embry Riddle Aeronautical University Daytona Beach. (2006). website from: http://www.erau.edu/db/index.html

Embry Riddle Aeronautical University Prescott. (2006). website from: http://www.erau.edu/pr/

Florida Institute of Technology College of Aeronautics. (2006). website from: http://coa.fit.edu

International Civil Aviation Organization. (2004). Manual on the implementation of ICAO language proficiency requirements (AN/453 Doc. 9835). Montreal, Quebec, Canada: Author.

Louisiana Tech University Department of Professional Aviation. (2006). website from: http://www.latech.edu/aviation/

Mathews, E. (2004). New provisions for English language proficiency are expected to improve aviation safety. ICAO Journal, 59(1), 4-6, 27.

Mesthrie, R., Swann, J., Deumert, A., \& Leap, W.L. (2000). Introducing Sociolinguistics. Philadepphia, PA: John Benjamins.

Middle Tennessee State University Aerospace. (2006). website from: http://aerospace.web.mtsu.edu/home.htm

Nordwall, B. D. (1997, September 29). FAA: English ATC standards needed. Aviation Week \& Space Technology, 147(13), 46-47.

Parks College of Engineering, Aviation and Technology. (2006). website from: http://parks.slu.edu/

Philips, D. (1991). Linguistic security in the syntactic structures of air traffic control English. English World-Wide, 12(1), 103-124.

Prinzo, O. V., \& Britton, T. W. (1993). ATC/pilot voice communications: A survey of the Literature. (NTIS No. DOT/FAA/AM-93/20).

Purdue University College of Technology Aviation Technology. (2006). website from: http://www.tech.purdue.edu/at/ 
Purdue University International Students and Scholars. (2004). Fall 2004 enrollment and statistical report. West Lafayette, IN.

Ragan, P. H. (2002, March). Deadly misunderstandings: language and culture in the cockpit. Paper presented at the First Annual Aviation Communications Conference, Phoenix, AZ.

St. Cloud State University Department of Aviation. (2006). website from: http://www.stcloudstate.edu/aviation/

University of North Dakota Aerospace Flight Operations. (2006). website from: http://www.avit.und.edu/f1_Home/index.php

University of Oklahoma Flight. (2006). website from: http://www.aviation.ou.edu

Utah State University Engineering \& Technology Education. (2006). website from: http://www.engineering.usu.edu/ete

Verhaegen, B. (2001). Safety issues related to language use have come under scrutiny. ICAO Journal, 56(2), 15-17, 30.

Western Michigan University College of Aviation. (2006). website from: http://www.wmich.edu/aviation/about.htm 


\section{APPENDIX}

Table A-1. CAA Accredited Flight Programs

Arizona State University, Mesa, Arizona

Auburn University, Auburn, Alabama

Central Missouri State University, Warrensburg, Missouri

Daniel Webster College, Nashua, New Hampshire

Embry-Riddle Aeronautical University, Daytona Beach, Florida

Embry-Riddle Aeronautical University, Prescott, Arizona

Florida Institute of Technology, Melbourne, Florida

Louisiana Tech University, Ruston, Louisiana

Middle Tennessee State University, Murfreesboro, Tennessee

Parks College of Engineering and Aviation of Saint Louis University, St. Louis, Missouri

Purdue University, West Lafayette, Indiana

St. Cloud State University, St. Cloud, Minnesota

University of North Dakota, Grand Forks, North Dakota

University of Oklahoma, Norman, Oklahoma

Utah State University, Logan, Utah

Western Michigan University, Kalamazoo, Michigan

*Accredited programs as of July, 2005.

\section{5-6 Enrollment}

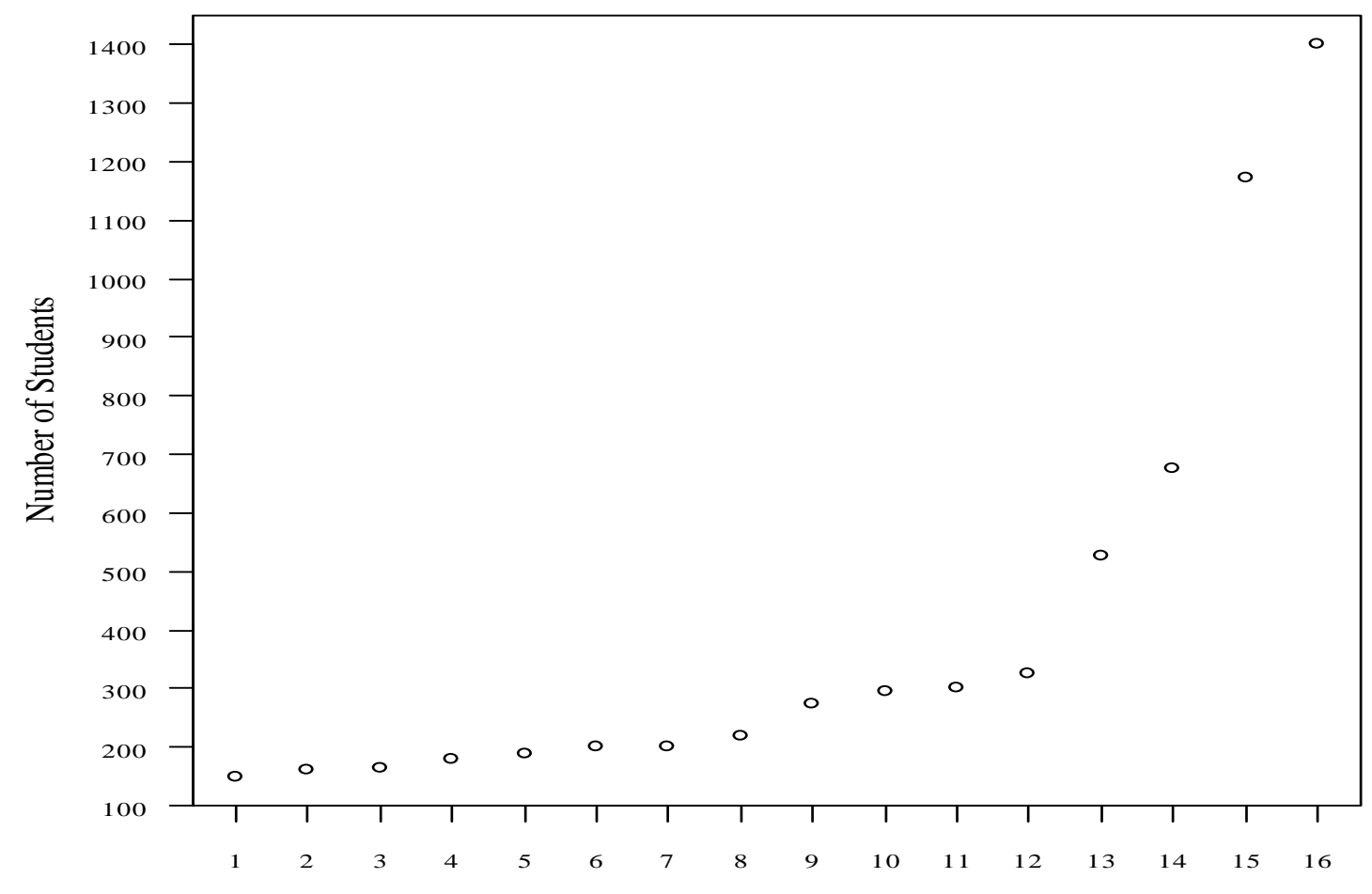

CAA Accredited Flight Programs

Figure A- 1. Flight Program Enrollment in Rank Order 


\section{5-6 International Student Enrollment}

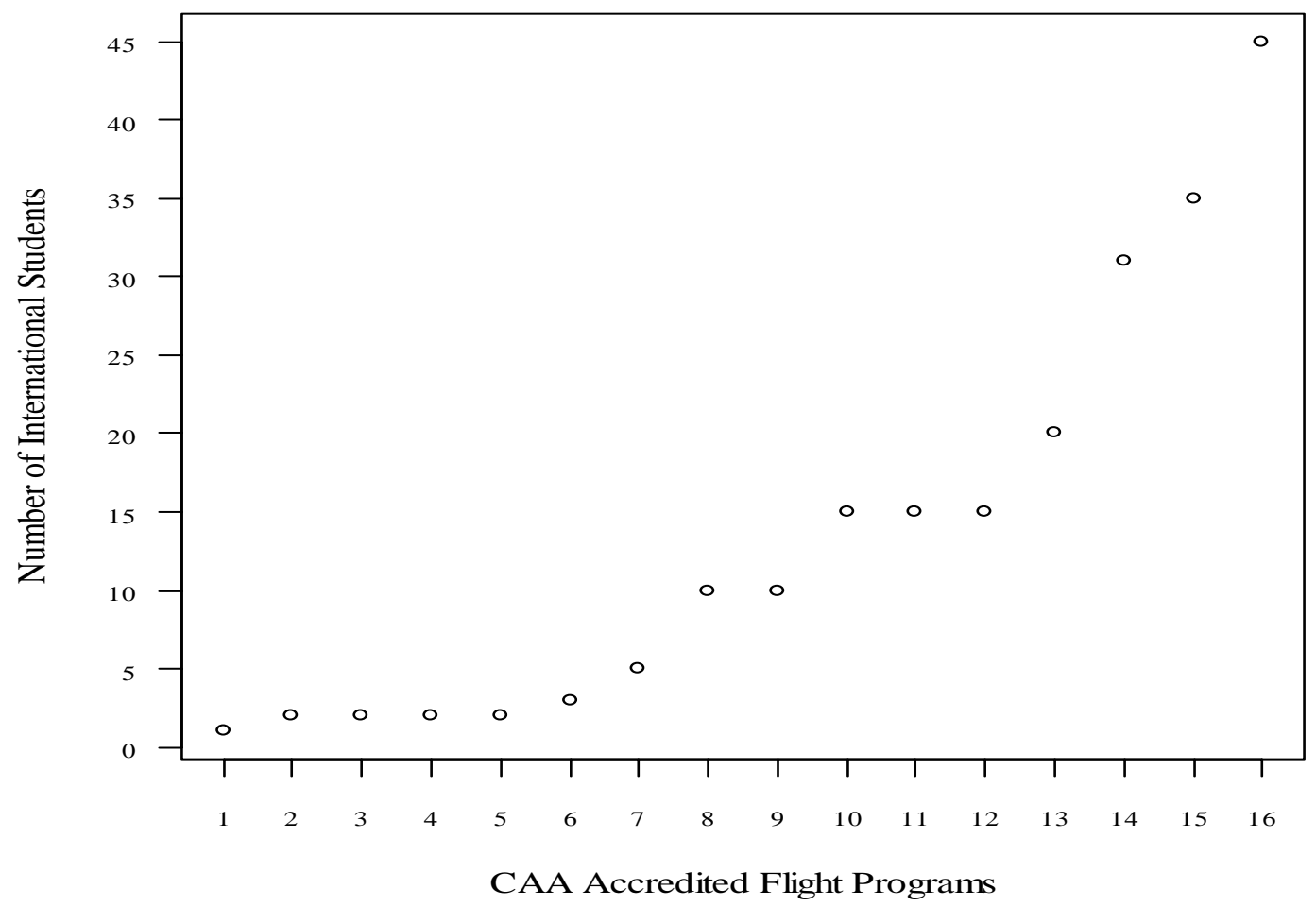

Figure A- 2. International Student Enrollment in Rank Order

\section{5-6 International Student Enrollment}

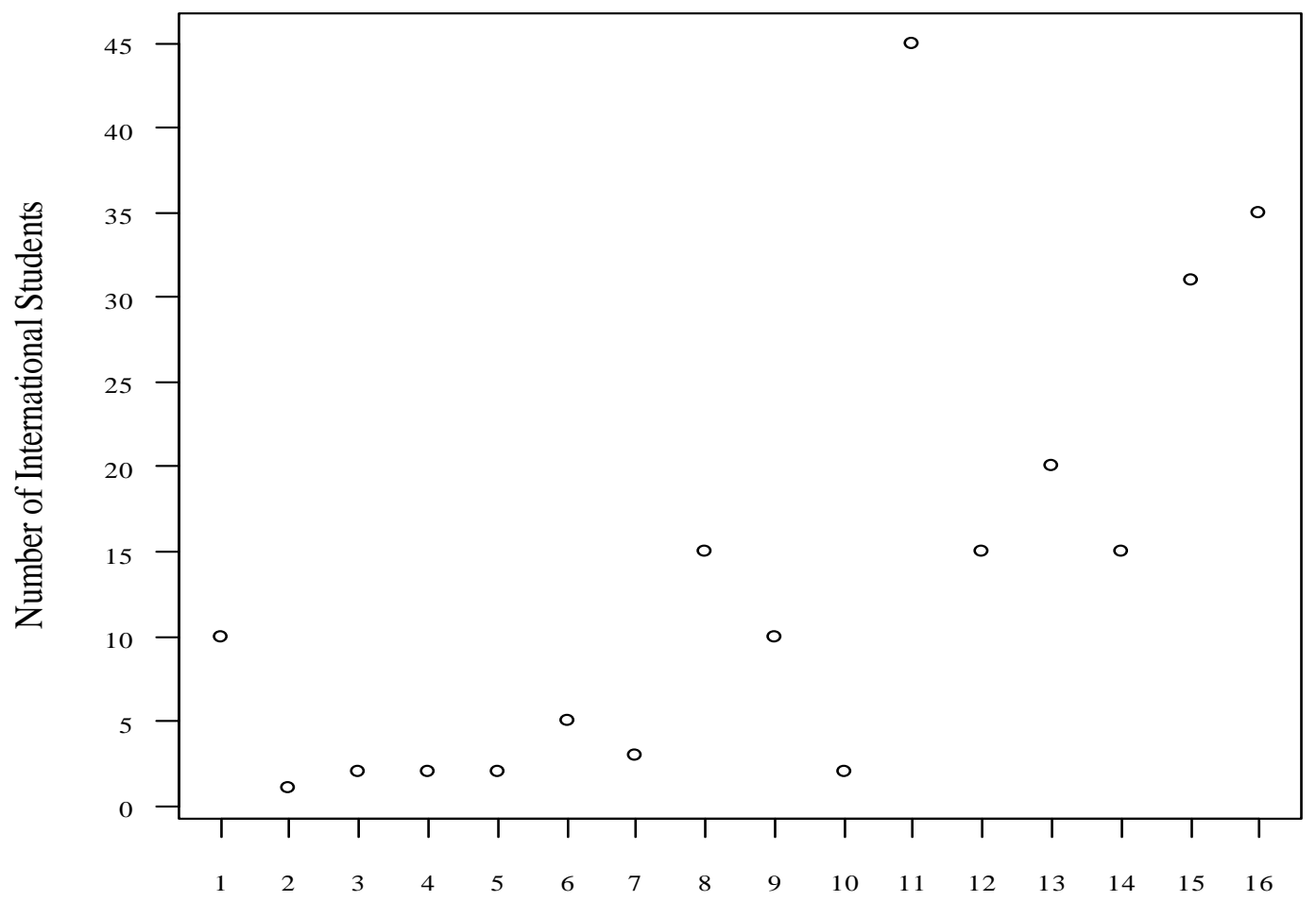

CAA Accredited Flight Programs

Figure A- 3. International Student Enrollment in Program Rank Order 


\section{5-6 Percentage International Student Enrollment}

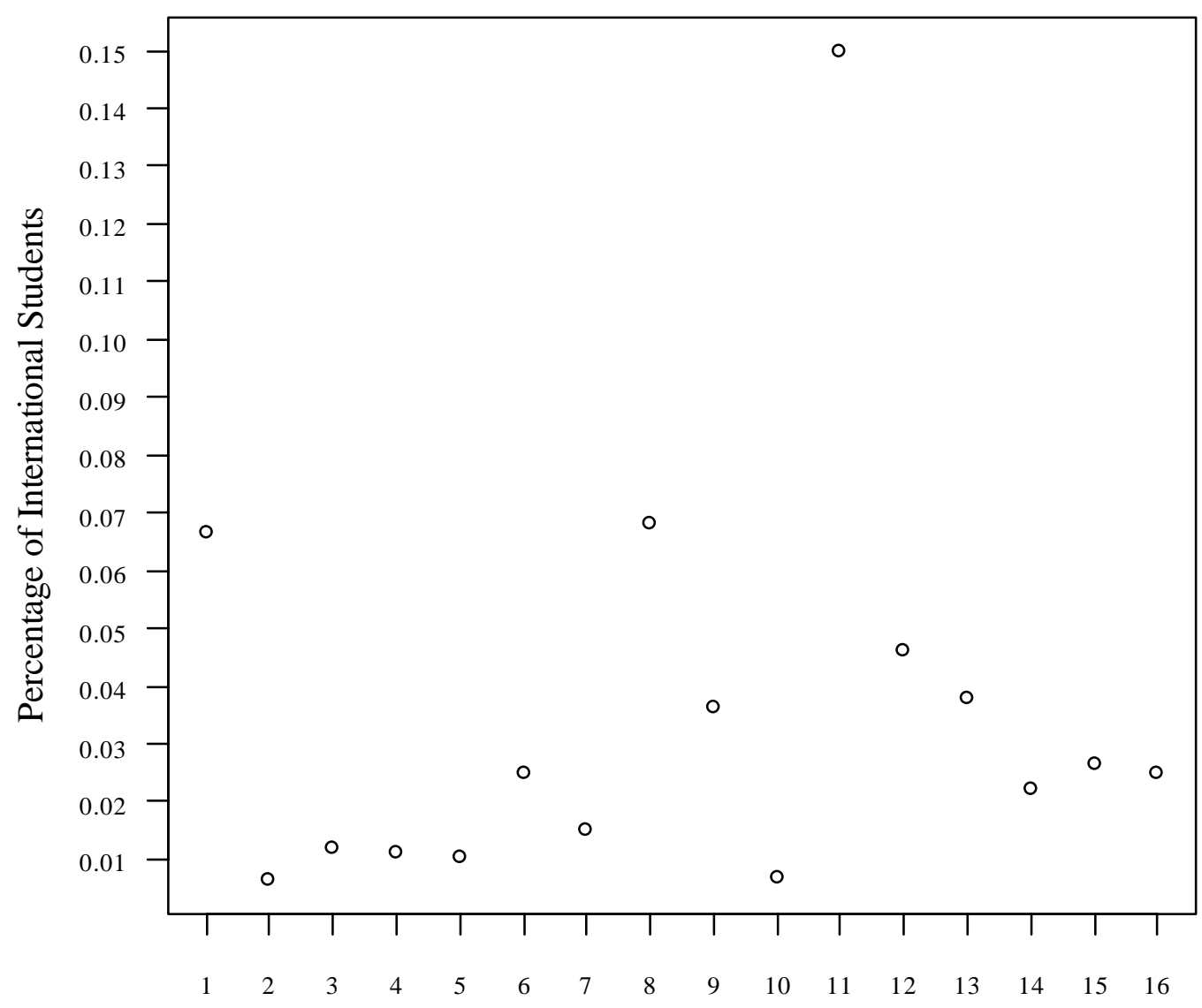

CAA Accredited Flight Programs

Figure A- 4. Percentage of International Students in Program Rank Order 
Table A 2. International Student Countries of Origin

\begin{tabular}{|c|c|c|}
\hline Country & Number of Programs & Response Rate \\
\hline Argentina & 2 & $12.50 \%$ \\
\hline Australia & 3 & $18.75 \%$ \\
\hline Austria & 2 & $12.5 \%$ \\
\hline Bangladesh & 1 & $6.25 \%$ \\
\hline Belgium & 1 & $6.25 \%$ \\
\hline Bolivia & 1 & $6.25 \%$ \\
\hline Brazil & 6 & $37.5 \%$ \\
\hline Bulgaria & 3 & $18.75 \%$ \\
\hline Canada & 6 & $37.5 \%$ \\
\hline Chile & 2 & $12.5 \%$ \\
\hline China, People's Republic of & 3 & $18.75 \%$ \\
\hline Columbia & 2 & $12.5 \%$ \\
\hline Costa Rica & 1 & $6.25 \%$ \\
\hline Croatia & 3 & $18.75 \%$ \\
\hline Cyprus & 1 & $6.25 \%$ \\
\hline Czech Republic & 2 & $12.5 \%$ \\
\hline Denmark & 2 & $12.5 \%$ \\
\hline Dominican Republic & 2 & $12.5 \%$ \\
\hline Ecuador & 2 & $12.5 \%$ \\
\hline Egypt & 3 & $18.75 \%$ \\
\hline El Salvador & 1 & $6.25 \%$ \\
\hline Ethiopia & 2 & $12.5 \%$ \\
\hline Finland & 2 & $12.5 \%$ \\
\hline France & 6 & $37.5 \%$ \\
\hline Germany & 6 & $37.5 \%$ \\
\hline Ghana & 1 & $6.25 \%$ \\
\hline Greece & 4 & $25.0 \%$ \\
\hline Guatemala & 2 & $12.5 \%$ \\
\hline Honduras & 2 & $12.5 \%$ \\
\hline Hungary & 2 & $12.5 \%$ \\
\hline Iceland & 2 & $12.5 \%$ \\
\hline India & 5 & $31.25 \%$ \\
\hline Indonesia & 2 & $12.5 \%$ \\
\hline Iran & 1 & $6.25 \%$ \\
\hline Ireland & 1 & $6.25 \%$ \\
\hline Israel & 1 & $6.25 \%$ \\
\hline Italy & 3 & $18.75 \%$ \\
\hline Jamaica & 5 & $31.25 \%$ \\
\hline Japan & 12 & $75.0 \%$ \\
\hline Jordan & 2 & $12.5 \%$ \\
\hline Kenya & 4 & $25.0 \%$ \\
\hline Kuwait & 3 & $18.75 \%$ \\
\hline Lebanon & 2 & $12.5 \%$ \\
\hline Luxembourg & 0 & $0.0 \%$ \\
\hline Malaysia & 2 & $12.5 \%$ \\
\hline Mexico & 4 & $25.0 \%$ \\
\hline Mongolia & 0 & $0.0 \%$ \\
\hline Morocco & 2 & $12.5 \%$ \\
\hline
\end{tabular}




\begin{tabular}{|c|c|c|}
\hline Country & Number of Programs & Response Rate \\
\hline Mozambique & 0 & $0.0 \%$ \\
\hline Nepal & 1 & $6.25 \%$ \\
\hline Netherlands & 4 & $25.0 \%$ \\
\hline New Zealand & 1 & $6.25 \%$ \\
\hline Nicaragua & 1 & $6.25 \%$ \\
\hline Nigeria & 1 & $6.25 \%$ \\
\hline Norway & 3 & $18.75 \%$ \\
\hline Pakistan & 3 & $18.75 \%$ \\
\hline Panama & 2 & $12.5 \%$ \\
\hline Peru & 1 & $6.25 \%$ \\
\hline Philippines & 2 & $12.5 \%$ \\
\hline Poland & 2 & $12.5 \%$ \\
\hline Portugal & 2 & $12.5 \%$ \\
\hline Romania & 2 & $12.5 \%$ \\
\hline Russia & 2 & $12.5 \%$ \\
\hline Saudi Arabia & 5 & $31.25 \%$ \\
\hline Singapore & 1 & $6.25 \%$ \\
\hline South Africa & 3 & $18.75 \%$ \\
\hline South Korea & 4 & $25.0 \%$ \\
\hline Spain & 2 & $12.50 \%$ \\
\hline Sri Lanka & 3 & $18.75 \%$ \\
\hline Sweden & 3 & $18.75 \%$ \\
\hline Switzerland & 3 & $18.75 \%$ \\
\hline Taiwan & 5 & $31.25 \%$ \\
\hline Thailand & 2 & $12.5 \%$ \\
\hline Trinidad and Tobago & 4 & $25.0 \%$ \\
\hline Turkey & 3 & $18.75 \%$ \\
\hline Ukraine & 2 & $12.5 \%$ \\
\hline United Arab Emirates & 3 & $18.75 \%$ \\
\hline United Kingdom & 5 & $31.25 \%$ \\
\hline Venezuela & 3 & $18.75 \%$ \\
\hline Vietnam & 2 & $12.5 \%$ \\
\hline Yugoslavia & 0 & $0.0 \%$ \\
\hline Zimbabwe & 2 & $12.5 \%$ \\
\hline other: Bahamas & 1 & $6.25 \%$ \\
\hline other: Liechtenstein & 1 & $6.25 \%$ \\
\hline
\end{tabular}

